\title{
Application of $\varphi$-IASI to IASI: retrieval products evaluation and radiative transfer consistency
}

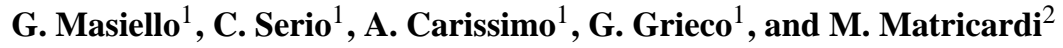 \\ ${ }^{1}$ Dipartimento di Ingnegeria e Fisica dell'Ambiente, University of Basilicata, 85100 Potenza, Italy \\ ${ }^{2}$ European Centre for Medium-Range Weather Forecasts (ECMWF), Shinfield Park, Reading, Berkshire, RG2 9AX, UK
}

Received: 22 February 2009 - Published in Atmos. Chem. Phys. Discuss.: 16 April 2009

Revised: 27 October 2009 - Accepted: 29 October 2009 - Published: 19 November 2009

\begin{abstract}
Retrieval products for temperature, water vapour and ozone have been obtained from spectral radiances measured by the Infrared Atmospheric Sounding Interferometer flying onboard the first European Meteorological Operational satellite. These products have been used to check the consistency of the forward model and its accuracy and the expected retrieval performance. The study has been carried out using a research-oriented forward-inverse methodology, called $\varphi$-IASI, that the authors have specifically developed for the new sounding interferometer. The performance of the forward-inversion strategy has been assessed by comparing the retrieved profiles to profiles of temperature, water vapour and ozone obtained by co-locating in space and time profiles from radiosonde observations and from the European Centre for Medium-Range Weather Forecasts analysis. Spectral residuals have also been computed and analyzed to assess the quality of the forward model. Two versions of the highresolution transmission molecular absorption database have been used, which mostly differ for ozone absorption line parameters, line and continuum absorption of both $\mathrm{CO}_{2}$ and $\mathrm{H}_{2} \mathrm{O}$ molecules. Their performance has been assessed by inter-comparing the results, and a consistent improvement in the spectral residual has been found when using the most updated release.
\end{abstract}

\section{Introduction}

The study presents and describes the application of the $\varphi$ IASI package (Grieco et al., 2007) to the retrieval of temperature, moisture and ozone from IASI (Infrared Atmospheric Sounding Interferometer) data obtained during the commissioning phase of the instrument in 2007.

Correspondence to: G. Masiello

(guido.masiello@unibas.it)
IASI has been developed by the Centre National d'Etudes Spatiales (CNES) of France, for the Metop-A (Meteorological Operational Satellite), the first of three satellites of the European Polar System (EPS) of EUMETSAT (European Organization for the Exploitation of Meteorological Satellites).

A historical background of the IASI instrument can be found in Bizzarri (1993). The design of the IASI instrument is based on a Michelson interferometer and its basic concept dates back to the work of Cayla (Cayla, 1993). Cayla's concept instrument was soon translated to expected retrieval performance for temperature, moisture and ozone by Amato et al. (1995); Amato and Serio (1997); Amato et al. (1997). Later contribution to the development of the instrument can be found at the web site, http://smsc.cnes.fr/ IASI/Fr/A_publications.htm.

Coming back to present days, the IASI data considered in this study were measured over the tropical basin. We have considered two datasets.

The first one is based on the Joint Airborne IASI validation experiment (JAIVEx) (Taylor et al., 2007), which was carried out in the United States during April and May 2007. The data set consists of 25 clear-sky, sea surface, IASI spectra, with time and space collocated radiosonde observations. These spectra have been used for radiance closure and, hence, to verify the quality and consistency of radiative transfer and spectroscopy.

The second dataset consists of 647 IASI spectra, which were measured during the IASI commissioning phase on 22 July 2007 over the tropical belts. For this second dataset of IASI observations, in-situ (truth) data consist of profiles for temperature, water vapour and ozone from the ECMWF analysis for the same date and location as those of the IASI soundings. This second data set has been mostly used for an independent check of IASI retrieval accuracy. The IASI retrieval has been obtained independently of the aforementioned ECMWF analysis. 
To simplify the comparison of retrieval products with truth data, only clear-sky, sea-surface IASI soundings have been analyzed in this work.

To assess the retrieval performance of the inversion scheme we have evaluated differences between retrieved and in-situ profiles of temperature, water vapour and ozone. In addition, spectral residuals for each inversion have been computed and compared to the IASI radiometric noise. To this end we have used two versions of HITRAN (highresolution transmission molecular absorption database), HITRAN 2000 (Rothman et al., 2003) and the most recent HITRAN 2004 (Rothman et al., 2005) with updates up to January 2007 (Gordon et al., 2007).

The paper is organized as follows. In Sect. 2 we describe the basic aspects of the forward-inverse methodology, $\varphi$-IASI. In Sect. 3 we describe the data used in the study and discuss the results. Conclusions are drawn in Sect. 4

\section{The $\varphi$-IASI package and its expected performance for IASI}

The package $\varphi$-IASI is intended to provide a kit of models to address research issues on inversion methodology (including Tikhonov and/or Rodgers regularization, LevenbergMarquardt least-square minimization) and radiative transfer (including generation of analytical derivative matrices, impact of new spectroscopy). The package has been the subject of various scientific papers and, in addition, it has been extensively validated using aircraft and satellite high spectral resolution infrared observations recorded with Fourier transform spectrometers (Amato et al., 2002; Carissimo et al., 2005; Taylor et al., 2008; Grieco et al., 2007). Here we discuss the basic aspects of the forward and inverse modeling, which are relevant to the present analysis.

\subsection{The forward model, $\sigma$-IASI}

The forward model, which we call $\sigma$-IASI, consists of a monochromatic radiative transfer model which has been designed for the fast computation of spectral radiance and its derivatives (Jacobian) with respect to a given set of geophysical parameters.

The forward module computes monochromatic radiances from look-up tables of monochromatic layer optical depth generated using the line-by-line model LBLRTM (Clough et al., 2005).

The atmospheric layering implemented in $\sigma$-IASI consists of a pressure layer grid of $N_{L}=60$ grid points. The definition of the model pressure levels is in Table 1.

Recent important improvements of $\sigma$-IASI include (Carissimo et al., 2009) a new analytical scheme for the computation of the radiance derivative with respect to $\mathrm{H}_{2} \mathrm{O}$ mixing ratio $q$, which takes into account the non-linearity of the spectral optical depth with respect to $q$ introduced by a)
Table 1. Definition of $\sigma$-IASI pressure levels.

\begin{tabular}{crrrrr}
\hline Layer & $\begin{array}{r}\text { Pressure } \\
{[\mathrm{hPa}]}\end{array}$ & $\begin{array}{r}\text { Layer } \\
\text { Pressure } \\
{[\mathrm{hPa}]}\end{array}$ & $\begin{array}{r}\text { Layer } \\
\text { Pressure } \\
{[\mathrm{hPa}]}\end{array}$ \\
\hline 1 & $1013-1005$ & 21 & $550-500$ & 41 & $55.3-53.2$ \\
2 & $1005-1000$ & 22 & $500-466$ & 42 & $53.2-51.1$ \\
3 & $1000-986$ & 23 & $466-432$ & 43 & $51.1-50.0$ \\
4 & $986-973$ & 24 & $432-400$ & 44 & $50.0-48.8$ \\
5 & $973-960$ & 25 & $400-350$ & 45 & $48.8-47.3$ \\
6 & $960-946$ & 26 & $350-300$ & 46 & $47.3-45.8$ \\
7 & $946-933$ & 27 & $300-275$ & 47 & $45.8-40.0$ \\
8 & $933-925$ & 28 & $275-250$ & 48 & $40.0-30.0$ \\
9 & $925-913$ & 29 & $250-225$ & 49 & $30.0-25.0$ \\
10 & $913-900$ & 30 & $225-200$ & 50 & $25.0-20.0$ \\
11 & $900-875$ & 31 & $200-175$ & 51 & $20.0-15.0$ \\
12 & $875-850$ & 32 & $175-150$ & 52 & $15.0-10.0$ \\
13 & $850-833$ & 33 & $150-122$ & 53 & $10.0-7.0$ \\
14 & $833-814$ & 34 & $122-100$ & 54 & $7.0-5.0$ \\
15 & $814-795$ & 35 & $100-85$ & 55 & $5.0-3.0$ \\
16 & $795-748$ & 36 & $85-70$ & 56 & $3.0-2.0$ \\
17 & $748-700$ & 37 & $70-65$ & 57 & $2.0-1.0$ \\
18 & $700-650$ & 38 & $65-60$ & 58 & $1.0-0.5$ \\
19 & $650-600$ & 39 & $60-57.5$ & 59 & $0.5-0.1$ \\
20 & $600-550$ & 40 & $57.5-55.3$ & 60 & $0.1-0.005$ \\
\hline
\end{tabular}

continuum absorption, and b) self-broadening absorption effect. Other new features include also the parallelization of the code that now can run almost in real time.

For the present version of $\sigma$-IASI, the required look-up tables have been generated with two different versions of LBLRTM,

- LBLRTM version 8.1, in which line parameters are taken from HITRAN 2000 including the 2001 modifications (Rothman et al., 2003). The continua come from MT_CKD version 1.0 (Tobin et al., 1999). The resulting $\sigma$-IASI version will be referred to in the following as release L8.1, or $\sigma$-IASILL8.1.

- LBLRTM version 11.3, released on November 2007. In this newest version the line parameters are obtained from the compilation aer_v_2.1 developed by AER Inc. of Massachusetts, USA. More details can be found at the web site http://rtweb.aer.com/line_param_whats_ new.html. This line compilation is derived from HITRAN 2004 (Rothman et al., 2005) and includes updates up to 1 January 2007 (e.g. for the water vapour it includes the diet of the air-broadened half-widths, Gordon et al., 2007). For the IASI spectral range the only differences between aer_v_2.1 and HITRAN2004 database are for the Carbon dioxide lines. In order to be consistent with the line coupling parameter derived by Niro et al. (2005), AER database uses the 2000 version of Carbon Dioxide line parameters. Furthermore, 
the continua adopted in LBLRTM v. 11.3 are the latest public release of the MT_CKD model. This version 2.1, for the water vapour, take into account the new values of the half-widths, while, as said above, the continuum for carbon dioxide has been calculated based on the new line coupling model developed by Niro et al. (2005). The resulting $\sigma$-IASI version will be refereed to in the following as release L11.3, or simply $\sigma$-IASI_L11.3.

To generate IASI synthetic spectra, the $\sigma$-IASI infinite resolution spectrum has to be convolved with the IASI Instrumental Spectral Response Function. To this end, a Gaussian instrument function with the Full-Width Half-Maximum (FWHM) prescribed for IASI, namely FWHM $=0.5 \mathrm{~cm}^{-1}$, has been used.

\subsection{The inverse model $\delta$-IASI}

The inverse module, which we call $\delta$-IASI, implements a non-linear inversion procedure, which need to be properly initialized as there may be multiple solutions due to the illposed nature of the retrieval problem. For the present study, the initialization is provided by the Empirical Orthogonal Function (EOF) statistical retrieval approach described in (Grieco et al., 2005; Serio et al., 2009).

The basic implementation of the inverse scheme follows Rodgers's statistical regularization method (Rodgers, 1976). However, an additional regularization parameter, $\gamma$ is introduced in the inverse scheme, which improves the retrieval accuracy and constrains the step size of Newton updates in such a way as to iterate towards the likely region of the inverse solution (Carissimo et al., 2005; Grieco et al., 2007).

For the present study, the following spectral ranges have been considered for the inversion of IASI data: 645 to $810 \mathrm{~cm}^{-1} ; 1010$ to $1080 \mathrm{~cm}^{-1} ; 1100$ to $1200 \mathrm{~cm}^{-1} ; 1450$ to $1600 \mathrm{~cm}^{-1} ; 2000$ to $2230 \mathrm{~cm}^{-1}$.

At the IASI sampling rate of $0.25 \mathrm{~cm}^{-1}$, this corresponds to a number of IASI spectral radiances, $n=2865$. The spectral location of these channels is shown in Fig. 1, which also allows us to exemplify the spectral quality of IASI data.

To apply $\delta$-IASI to the observations, we need the IASI observational covariance matrix, C. For the present work, this has been assumed to be diagonal and computed according to

$$
\mathbf{C}=\mathbf{O}+\mathbf{F}
$$

with $\mathbf{O}$ the observational covariance matrix made up with the apodized level 1C IASI radiometric noise. The reader interested to understand how apodization affects noise and retrieval is referred to Amato et al. (1998).

The matrix $\mathbf{F}$ models the forward model noise, and for the work here presented $\mathbf{F}$ is chosen to be proportional to $\mathbf{O}$,

$\mathbf{F}=f^{2} \mathbf{O}$

where $f$ is a tuning parameter, which can be properly scaled in order to yield a final iterate, which produces a $\chi^{2}$ value be-

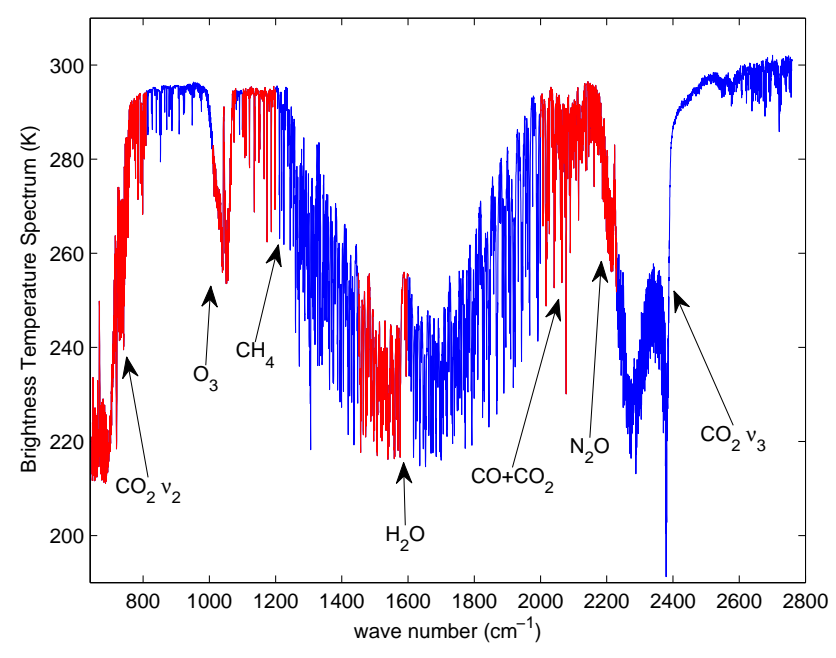

Fig. 1. Example of IASI spectrum (in units of brightness temperature) showing (in red) the spectral ranges or channels used for inversion of temperature, water vapour and ozone profiles. The spectrum has been recorded on 29 April 2009 in the Gulf of Mexico during the JAIVEx campaign

low a given thresholds, $\chi_{\mathrm{th}}^{2}$. The $\chi^{2}$ function is here defined as usual

$\chi^{2}=\delta \boldsymbol{R}^{t} \mathbf{C}^{-1} \delta \boldsymbol{R}$

where $\delta \boldsymbol{R}$ is the spectral residual defined as observed minus calculated radiances.

A normal $\delta$-IASI run is assumed to have attained to a converged solution, when the calculated $\chi^{2}$ is below $\chi_{\mathrm{th}}^{2}$, which for the analysis at hand is set equal to a $\chi^{2}$ variable with $n$ degrees of freedom at a tolerance limit of $95 \%$. If we work with normalized quantities $\chi^{2} / n$, then the threshold is simply, $\chi_{\mathrm{th}}^{2} / n \approx 1$. Normally, the degrees of freedom, $n$ are equal to the number of spectral radiance data points or, equivalently, the size of the radiance vector, $\boldsymbol{R}$ minus the number of parameters estimated from the radiance vector itself for the generation of the first guess. The number of these parameters is equal to the number of EOF scores that in our scheme is normally 12,14 and 25 for temperature, water vapour and ozone, respectively. Because of the orthogonality property of principal components, we estimate from the radiance vector a total of parameters given by $\max (12,14,25)=25$. This figure may be compared with the number of spectral radiance data points, $n=2865$.

With the above fitting procedure we can assess the degree of consistency among observations and computations and a measure of this consistency is just the index $f^{2}$. The case $f^{2}=0$ corresponds to a perfect forward model. The larger $f^{2}$ is and the higher the inconsistency is. This simple procedure allows us to measure the inconsistency in terms of an additive source of pseudo noise, which may be compared directly to the size and magnitude of the IASI radiometric noise. 
As said before, this pseudo noise mostly arises from forward modeling errors, which, in turn, may have different sources: error in representing continuous parameters of altitude (such as temperature, water vapour and ozone) with discrete functions defined on a pressure/altitude mesh of atmospheric layers, residual cloud contamination in the radiances, uncertainty in the surface emissivity and trace gases that are not in the set of retrieved parameters, parameterizations of monochromatic transmittances in look-up tables, and last but not least spectroscopy errors in absorption line positions and strengths and related continua.

Because we know that there is a forward model noise, it is not prudent to yield inversions with $f=0$, since we could experience biases in the retrieval because of data overfitting. The choice of $f$ is a matter of trial and error and depends on the quality of data and spectroscopy. As an example for the JAIVEx data we were able to run with $f^{2}=0.96$, a rather small value, which is likely the result of the careful inspections for calibration of IASI spectra and highly confident clear sky IASI field of view obtained for this experiment. For the case of the second set of IASI data, which we had to retrieve directly from EUMETcast and qualify for clearsky with a IASI stand alone cloud detection algorithm, we were able to run with a value of $f^{2}=3-5$.

\subsection{1 $\delta$-IASI expected performance for IASI}

The expected retrieval performance for IASI of the inverse scheme has been assessed in simulation using the Chevalier (2001) data base for temperature, water vapour and ozone, $(T, q, o)$ profiles. For the analysis shown here, we have considered only clear-sky sea-surface and tropical profiles. This subset is made up of 377 individual profiles for $(T, q, o)$ and has been also used to train the EOF statistical initialization scheme.

Normally, $\delta$-IASI retrieves the skin temperature and $(T, q, o)$ profiles. The other atmospheric parameters are set to their climatological values. For gas species concentrations we use the compilation by Anderson et al. (1986). The fast forward model, $\sigma$-IASI is designed to deal with a variable $\mathrm{CO}_{2}$ mixing ratio profile. For the work reported here we have assumed a constant mixing ratio of 385 ppmv in every atmospheric layer. This value is that observed for the period of April 2007 (the date of the JAIVEx experiment) according to the NASA Earth System Monitoring Laboratory (Global Monitoring Division, e.g. see http://www.esrl.noaa.gov/gmd/ $\mathrm{ccgg} /$ trends/). Finally, surface emissivity including its dependence on the scan angle, is that derived by Masuda's model (Masuda et al., 1988) for sea surface and a mean wind speed of $5 \mathrm{~m} / \mathrm{s}$.

In performing the simulation exercise we have assumed a perfect knowledge of spectroscopy and forward model, so that the performance shown in Figs. 2 to 4 has to be interpreted as the best performance we could achieve with our methodology.

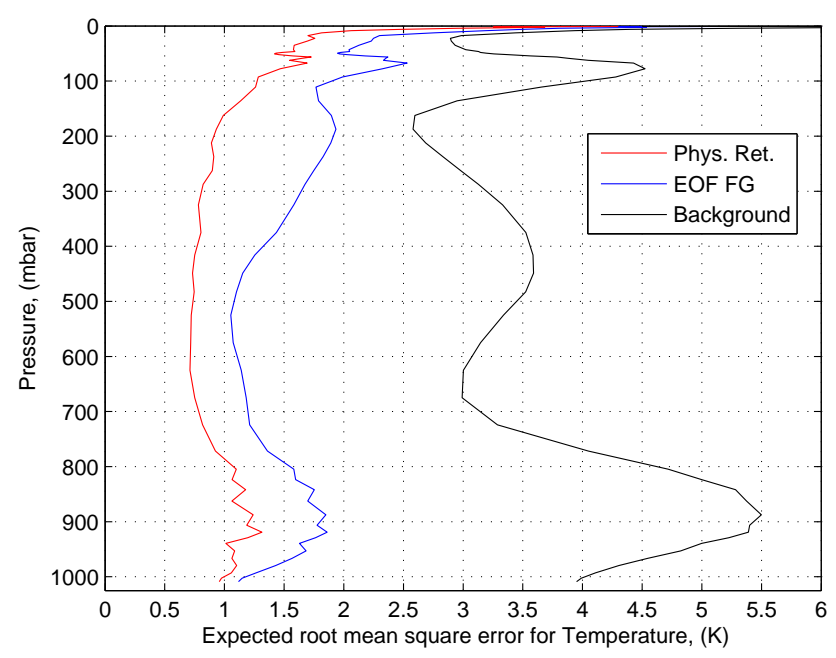

Fig. 2. Expected IASI temperature retrieval accuracy for tropical soundings. The figure compares the accuracy provided by the mean value of the training data set (computed as standard deviation of the ensemble of test profiles, this is referred to as background in the figure) to the ones obtained with the EOF regression scheme, and finally the final inversion step, respectively.

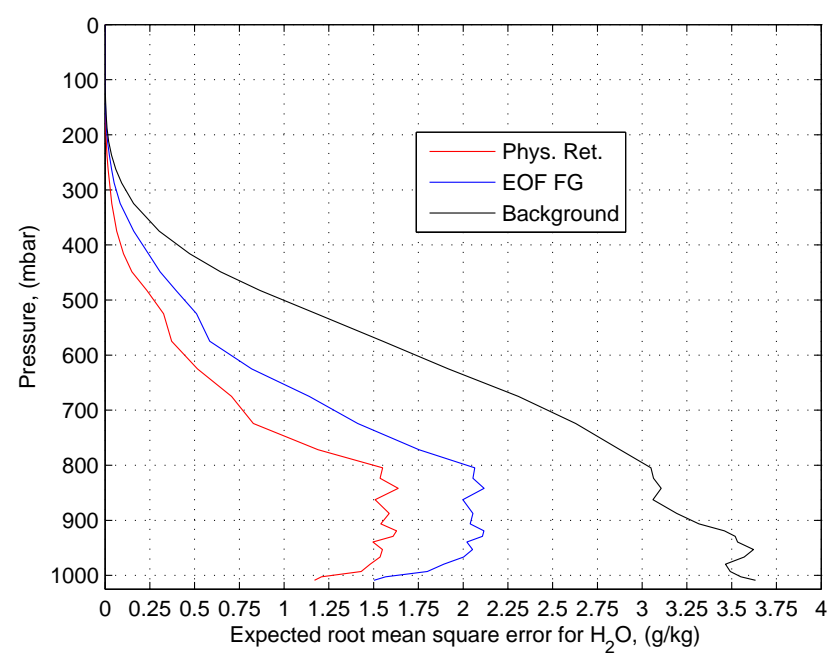

Fig. 3. As Fig. 2, but for water vapour.

Figure 2 shows the expected retrieval accuracy for temperature. The figure shows the root mean square error, $r$ as obtained after the EOF regression and the final inversion step. For comparison the standard deviation of the ensemble of the 377 test profiles is shown, as well. The root mean square error, $r(p)$ at any given pressure-layer, $p$ is computed as usual,

$r(p)=\left[\frac{1}{m} \sum_{i=1}^{m}(\hat{X}(p ; i)-X(p, i))^{2}\right]^{1 / 2}$ 


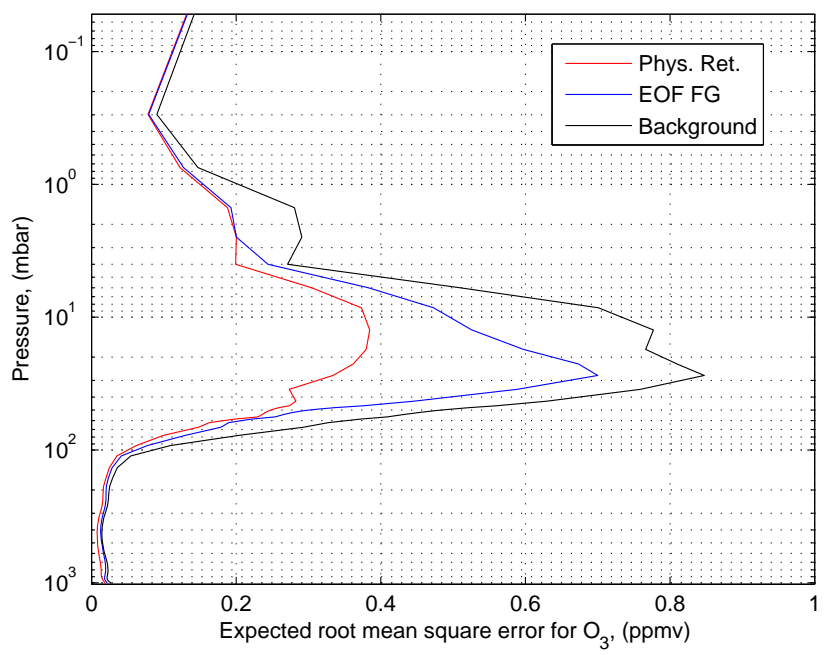

Fig. 4. As Fig. 2, but for ozone.

where $X(p, i)$ indicates a generic parameter at pressure, $p ; i$ labels the number of test cases, $i=1, \ldots, m$, with $m=377$; the retrieved estimate of $X$ is indicated with $\hat{X}$.

It is interesting to see, from Fig. 2, that the EOF regression improves the performance over the simple estimate given by the mean value of the training data set and that the inversion improves at any altitude level the accuracy of the retrieval. Based on the inverse scheme estimate, the expected temperature retrieval accuracy for IASI is quite close to the target accuracy of $1 \mathrm{~K}$ in the troposphere.

Figure 3 shows the expected water vapour retrieval performance. Again based on the final inversion step, the root mean square error in the lower troposphere ranges in between 1 to 1.5 , corresponding to a percentage error of $10 \%$ to $20 \%$, which is larger than the target accuracy of $10 \%$. It is important to stress here that our retrieval scheme uses mostly information from the data themselves. We do constrain the solution with information from the Chevalier data set, but this imposes a rather loose constraint to the final solution (details of how we constrain the inverse solution can be found in Grieco et al. (2007)). In addition, we remark that what is shown in Fig. 3 is the best achievable performance with our method. In other words, unless the data are bounded with much more informative constraints, such as done in the normal practice of a data assimilation system, which uses, e.g., forecast fields available from Numerical Weather Prediction centers, IASI will not perform better than $10-20 \%$, as far as the retrieval accuracy of water vapour is concerned.

For ozone, the expected performance is shown in Fig. 4. The root mean square error is confined below $10 \%$ in the region (around $10 \mathrm{mbar}$ ) where we normally observe the peak concentration of this atmospheric gas.

To complete the retrieval performance analysis, we have also computed the bias, $b(p)$ which, using the same notation
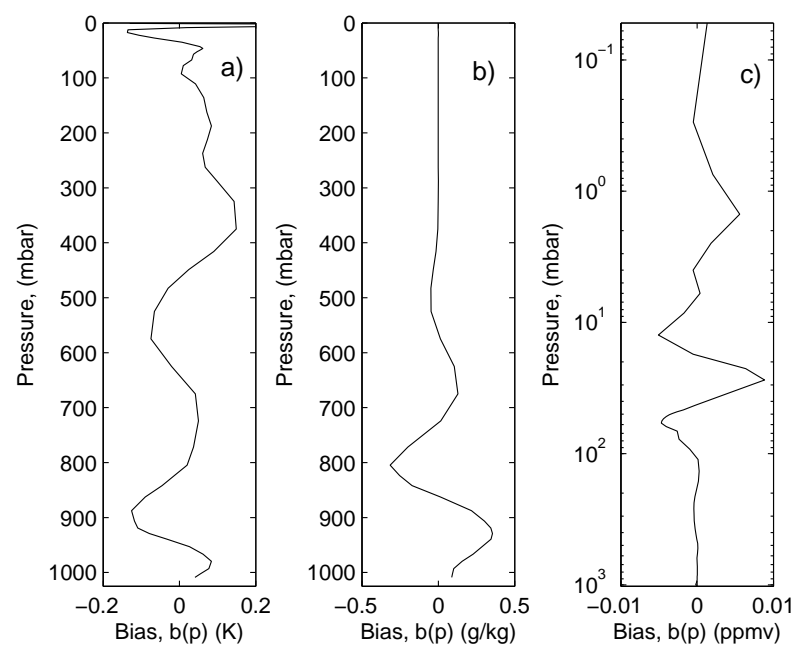

Fig. 5. Bias, indicated as $b(p)$ in figure, for the physical retrieval for (a) temperature, (b) water vapour, (c) ozone. Note the logarithmic scale for the pressure axis in the case of ozone.

as done for the root mean square error, is defined according to

$b(p)=\frac{1}{m} \sum_{i=1}^{m}(\hat{X}(p ; i)-X(p, i))$.

For the case of temperature, it is interesting to note that the bias (shown in Fig. 5a) is less than $0.1 \mathrm{~K}$ in the troposphere.

For the case of $\mathrm{H}_{2} \mathrm{O}$ the bias oscillates between $\pm 0.3 \mathrm{~g} / \mathrm{kg}$ in the lower part of the atmosphere (see Fig. 5b), a value which is almost negligible when compared to typical concentrations of this gas in tropical settings. Furthermore, the integral of this bias along the atmospheric column tends nearly to zero, which means that the columnar amount is largely unbiased.

Finally, for ozone the magnitude of bias (shown in Fig. 5c) is in any case fairly low and tends to oscillate around the zero line, which means that the retrieved atmospheric columnar amount of $\mathrm{O}_{3}$ is fairly unbiased. However, for the case of ozone it is fair to observe that the very good performance could be an artifact of the limitations of the test data set (the Chevalier data base), which for the case of ozone is made up of very smooth vertical profiles.

The analysis of the spatial vertical resolution of the retrieved profiles that are produced by $\delta$-IASI has been discussed at length in various papers. A comprehensive discussion can be found in Grieco et al. (2007). The analysis shows that retrieved profiles tend to be highly correlated along the vertical.

In addition to the well known, and sometimes abused, methodology of averaging kernels (which dates back to Backus and Gilbert, 1968) the interdependency along the vertical of the retrieved parameters can be assessed with the help 
of the $i_{D}$ index introduced by Serio et al. $(2008,2009)$. This index works on the a-posteriori covariance matrix of retrieval and may assume values from 1 to $N_{L}$, with $N_{L}$ the number of atmospheric layers used to render the vertical profile of the given parameter. In other words, $N_{L}$ is the size of the generic inverted vector, $\hat{X}$ (for our analysis $N_{L}=60$ ).

The index, $i_{D}$ should not be confused with the usual degrees of freedom, d.o.f., used in the Optimal Estimation methodology (see e.g. (Grieco et al., 2007)). The d.o.f determines how many pieces of independent (from the background) information are contributed by the data points, whereas our $i_{D}$ quantify how the given retrieval is correlated along the vertical.

The value, $i_{D}=1$ simply means that for the retrieval at hand it is as if the full atmosphere had been divided just in one layer, that is only the columnar amount of the parameter has been resolved. On the opposite edge of the $i_{D}$ scale, we have $i_{D}=N_{L}$, and the retrieval has been fully resolved on the grid mesh used to divide the atmosphere. Nearby layers can then, e.g., be used to form average quantities and, therefore, reduce the estimation error.

A detailed account of how $i_{D}$ is defined and computed can be found also in Amato et al. (2009). For the simulation exercise at hand, if we denote with $\delta \hat{X}$ the difference (retrievaltest) for the generic parameter $X$, then the a-posteriori covariance matrix can be estimated by considering the expectation value of $(\delta \hat{\mathbf{X}})(\delta \hat{\mathbf{X}})^{t}$. Then, the $i_{D}$ index can be easily computed from this matrix (Serio et al., 2008, 2009). We have found: $i_{D}=6.3$ for temperature; $i_{D}=4.3$ for water vapour; $i_{D}=2.9$ for ozone.

These values say that much of the information in the IASI data is reserved to temperature, less for water vapour and even less for ozone. However, for ozone it is important to stress that IASI is capable of retrieving three pieces of information, a result which is also confirmed in the recent work by Emerenko et al. (2008). The modest value for $\mathrm{H}_{2} \mathrm{O}$ says that only very coarse features of the water vapour profile are within the IASI capability.

\section{Application to IASI data and results}

\subsection{IASI and truth data}

As said before, we are dealing in this study with two sets of IASI data:

1. the first set has been derived from the 2007 JAIVEx campaign (see Taylor et al., 2007 for more details) over the Gulf of Mexico. We have a series of 6 spectra for the day 29 April 2007, 16 spectra for the day 30 April 2007, and finally 3 spectra for the day 4 May 2007. The total of 25 soundings are well collocated with radiosonde observations, as shown in Fig. 6. The spectra where recorded for clear sky fields of view, selected based

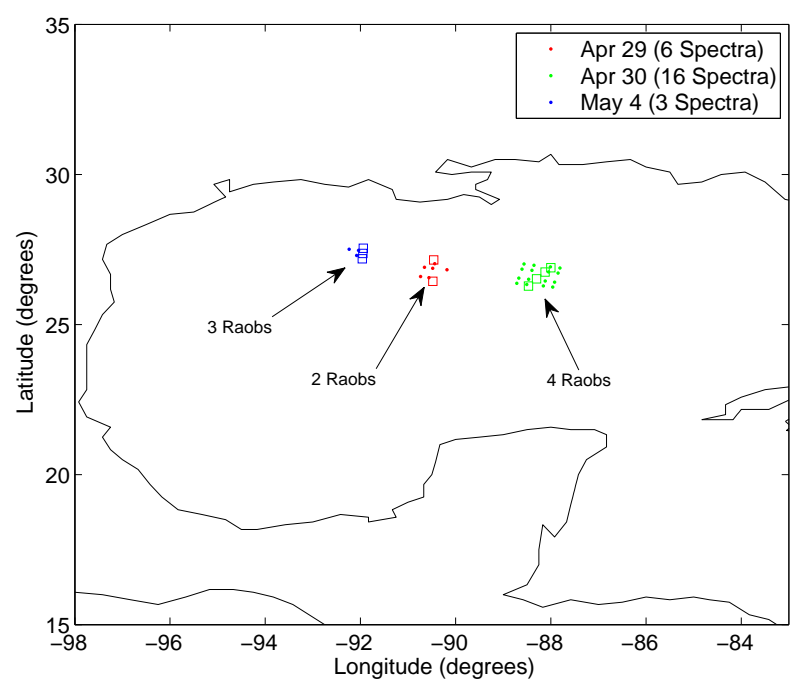

Fig. 6. IASI footprints and radiosonde observations for the JAIVEx data used in this paper.

on high resolution satellite imagery from AVHRR (Advanced Very High Resolution Radiometer) on MetOp (Meteorological Operational Satellite) and in-flight observations. Furthermore, the data for the day 29 April 2007 correspond to a nadir IASI field view, whereas those for the other two days to a field of view of 22.50 degrees.

2. A second data set has been acquired during the IASI commissioning phase on 22 July 2007 . The geolocation of these soundings can be seen in Fig. 7. In total, a number of 647 IASI spectra has been selected. The spectra have been observed on sea surface and refer to nadir looking mode and clear sky conditions. Clear sky was checked using the cloud detection scheme described in (Masiello et al., 2003; Grieco et al., 2007). This second set of data will be referred to as simply the tropical set.

For the tropical set, in order to develop a consistent set of truth data against which IASI retrieval could be compared, ECMWF atmospheric analysis fields for temperature, water vapor and ozone were considered. These fields where time and spatially co-located to the 647 IASI soundings. We used atmospheric analysis fields of 00:00, 06:00, 12:00, 18:00 and 24:00 UTC on 22 July 2007.

At that time, the ECMWF model was characterized by a vertical discretization of the atmosphere into 60 pressure levels and a horizontal grid spacing of about $40 \mathrm{~km}$ or, equivalently, to a horizontal grid box of $0.351^{\circ} \times 0.351^{\circ}$. The model has a hybrid vertical coordinate, with terrain-following coordinates in the lower troposphere and pressure coordinates in the stratosphere above about $70 \mathrm{hPa}$. Of the 60 levels in the vertical, 25 are above $100 \mathrm{hPa}$ and the model top is at $0.1 \mathrm{hPa}$, 


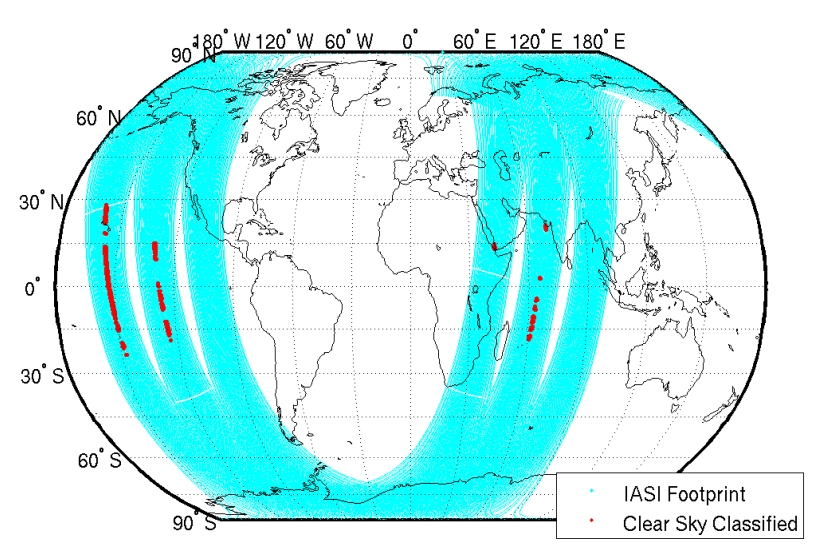

Fig. 7. IASI orbits for the day 22 July 2007 and clear sky footprints (in red) considered in this analysis.

corresponding to about $65 \mathrm{~km}$. The vertical resolution of the analysis fields gradually decreases from $20 \mathrm{~m}$ at the surface to about $250 \mathrm{~m}$ at $1 \mathrm{~km}$ altitude, and about $1 \mathrm{~km}$ to $3 \mathrm{~km}$ in the stratosphere. The analysis fields were extracted from the ECMWF archive at the full spatial resolution, interpolated to a grid of points with a separation of $0.3^{\circ} \times 0.3^{\circ}$ and then co-located to the IASI soundings. The statistics of the difference between global radiosonde observations and ECMWF analysis in the troposphere show values of the standard deviation typically between $0.5 \mathrm{~K}$ and $1 \mathrm{~K}$ for temperature and between 0.5 and $1.5 \mathrm{~g} / \mathrm{kg}$ for water vapour. In addition to fields of temperature, water vapour and ozone, ECMWF fields of sea-surface temperature (SST) were also used in the study. It should be noted that these fields are based on analyses received daily from the National Centers for Environmental Prediction (NCEP), Washington DC, on a $0.5^{\circ} \times 0.5^{\circ}$ grid.

\subsection{Results: radiance closure experiment and forward modelling consistency as derived from JAIVEx data}

The analysis performed in this study have been carried out with two different releases of $\delta$-IASI, which use different version of the forward model: namely $\sigma$-IASI_L8.1 and $\sigma$ IASI_L11.3. The reader is referred to Sect. 2.1 for the details about the difference between these two implementations.

The two $\delta$-IASI packages have been used to yield inversions for temperature, water vapour and ozone from the 25 JAIVEx spectra. As a by product, the process produces also the corresponding 25 best-fit synthetic spectra, computed on the basis of the final retrieved state vector. Observations and best fitted spectra have been used to compute the spectral residual.

The spectral residual is defined according to

$$
\delta \boldsymbol{R}=\boldsymbol{R}_{\text {iasi }}-\boldsymbol{R}_{\text {fit }}
$$

with $\boldsymbol{R}$ the spectral radiance and the subscripts iasi and fit denote the observation and the fitted spectrum at the end of the inversion procedure.

The spectral residual, averaged over the full set of 25 JAIVEx IASI soundings is shown in Fig. 8 for the two runs, that is $\sigma$-IASI L8.1 and L11.3, respectively. Figure 9 shows the same spectral residuals, but in units of brightness temperature $(\mathrm{K})$, for the range 645 to $2250 \mathrm{~cm}^{-1}$, which is the range we use in our inversion methodology.

\subsection{1 $\sigma$-IASI version L8.1}

It is immediately seen from Fig. 8 (or equivalently Fig. 9) that the mean spectral residual (shown in Fig. 8a for the case L8.1) does not tend to zero as it should be for an ideal case in which we had a perfect forward model. For comparison, Fig. 8a also shows the IASI radiometric noise. Because we have averaged 25 spectra, in case of a perfect random noise, the mean spectral residual should be a factor of $\sqrt{(25)}=5$ lower that the IASI radiometric noise. This is not the case, and we remark that in order to achieve convergence of the inversion procedure, within the $\chi^{2}$ metric, we had to put $f^{2}=0.96$ (see discussion in Sect. 2.2.1). This means that the forward model noise is about one half of the IASI radiometric noise.

However, this additional source of noise is not random. In fact, from Fig. 8a we see that it is strongly patterned and the shape of the patterns follow the shape of the various absorption bands.

One pattern is most evident from Fig. 8a, which exceeds the IASI noise. It coincides with the methane absorption band, centered at $1350 \mathrm{~cm}^{-1}$. The large misfit is due to the fact that it is not included among the retrieved parameters. A second, less evident discrepancy is seen in the $\mathrm{CO}$ weak band in the short wave side of the IASI spectrum at $2140 \mathrm{~cm}^{-1}$. Again, carbon monoxide was not included within the retrieved parameters. For both methane and carbon monoxide we used climatology.

For the $\mathrm{CO}_{2} \nu_{2}$-band at $667 \mathrm{~cm}^{-1}$, we have that the spectral residual is comparable with the IASI noise. Nevertheless it is patterned and not symmetric around zero. The patterns also follow the signature of absorption lines.

For the ozone band at $1040 \mathrm{~cm}^{-1}$ we also see a relatively large inconsistency, with marked signatures which are likely due to a lack of correct spectroscopy.

For water vapour, we still see an imperfect rendering of absorption features from the forward model. Also evident, across all the absorption band at $6.7 \mu \mathrm{m}$, is a slight but consistent hot bias, which is likely a problem of $\mathrm{H}_{2} \mathrm{O}$ continuum.

Nevertheless, the retrieval performance is fairly good for both temperature and water vapour, as it is possible to see from Fig. 10. The performance is in line with what is expected from the simulation analysis we have shown in Sect. 2.2.1. The root mean square error shown in Fig. 10 

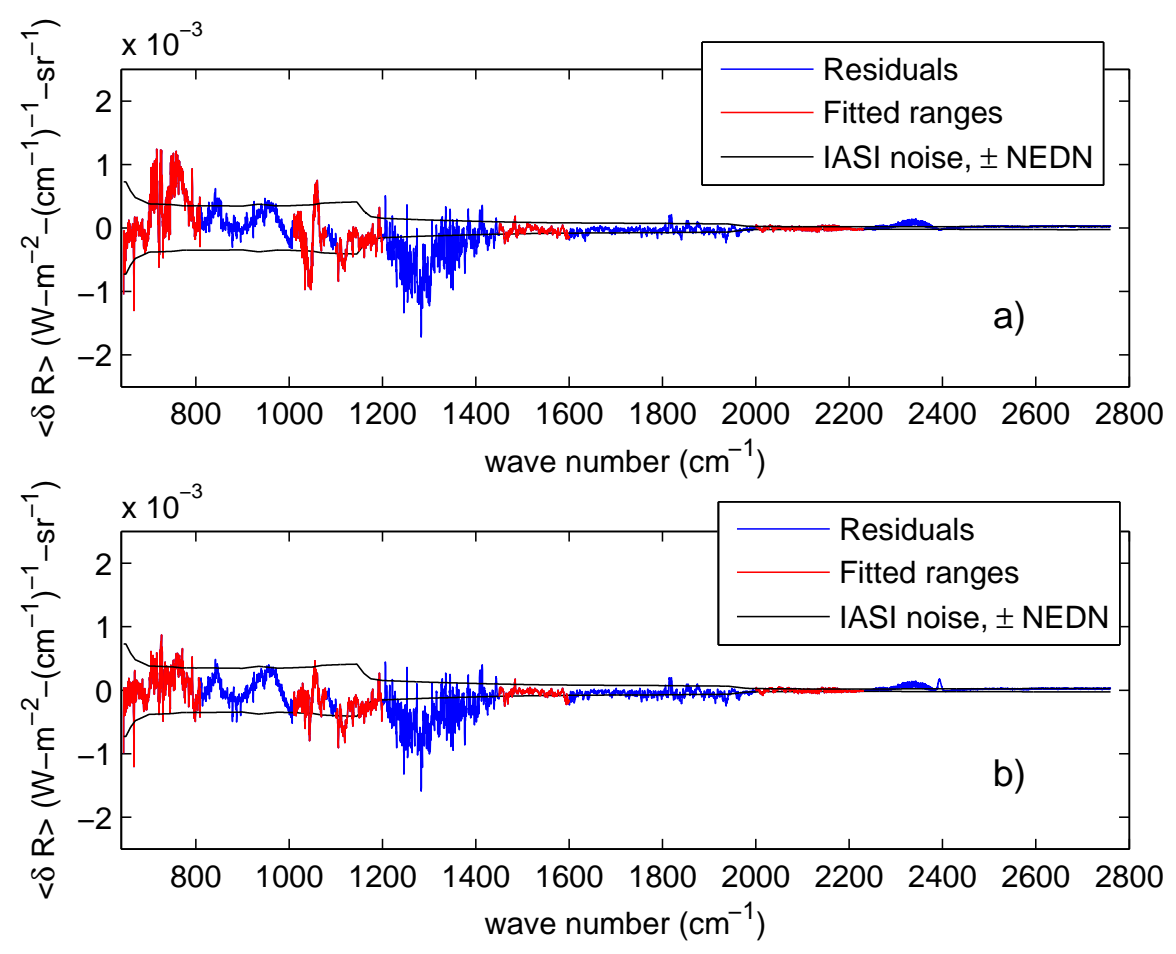

Fig. 8. Spectral residual, $\delta \boldsymbol{R}$ averaged over the 25 JAIVEx IASI soundings analyzed in this paper. (a) spectral residual for the case L8.1, (b) spectral residual for the case L11.3. The residuals in red corresponds to the spectral ranges, which have been used in the inversion process.

has been calculated by contrasting retrievals against the radiosonde observations.

\subsection{2 $\sigma$-IASI version $L 11.3$}

The spectral residual, averaged over the 25 IASI soundings, for the case L11.3 is shown in Fig. 8b (see also Fig. 9b). By comparing to Fig. 8a (and Fig. 9a), we see a fair improvement for the ozone band at $1040 \mathrm{~cm}^{-1}$ and a more modest one for the $\mathrm{H}_{2} \mathrm{O} v_{2}$-absorption band at $1600 \mathrm{~cm}^{-1}$. In addition we see a very significant improvement in the range 640 to $800 \mathrm{~cm}^{-1}$ of the $\mathrm{CO}_{2} v_{2}$-absorption band. This is the most consistent and striking improvement we see with the version L11.3 in comparison to the older L8.1. We think that this is a direct effect of the fact that for the version L8.1 we have only Q-branch line mixing treatment, whereas for the version L11.3 that uses the new model by Niro et al. (2005), the treatment includes all $\mathrm{P}, \mathrm{Q}$ and $\mathrm{R}$ lines.

This spectral improvement is in part reflected in a better performance for temperature, as it is possible to see from Fig. 10. Compared to the version L8.1, the improvement for the temperature profile is consistent in the lower troposphere. However, no significant improvement is seen for water vapour.

The relatively good results for the Q-branch at $667 \mathrm{~cm}^{-1}$ might be not in line with what is shown in concurrent analysis by other authors, e.g. see Shephard et al. (2009); Ma- tricardi (2009), who show a relatively larger discrepancy at $667 \mathrm{~cm}^{-1}$. However, as correctly suggested by Shephard et al. (2009), the magnitude of the discrepancy is particularly sensitive to the temperature profile. In our case the inversion process is initialized with EOF regression, which allows us to use a profile, which has been already tuned on the IASI observations, whereas in the case discussed by Shephard et al. (2009), the inversion process was initialized with the radiosonde observations, extended in the upper atmosphere via ECMWF analysis. If we follow the same approach, we get a residual which compares much better with that shown by Shephard et al. (2009), as is shown in Fig. 11.

Figure 11 evidences that in the longwave $\mathrm{CO}_{2}$ absorption band we have no important pathology for spectroscopy or forward modeling and apparent discrepancies are mostly due to incorrect shape of the temperature profile. However, unfortunately, this is not the case for the $v_{3}$ band, where a possible excess of continuum absorption is likely to affect the latest version of LBLRTM. This is very well evidenced by the behaviour of IASI and fitted spectra at the bandhead of the $\mathrm{CO}_{2} v_{3}$ spectral region. The comparison is provided in Fig. 12 and confirms an excess of continuum absorption of L11.3 in comparison to L8.1. In fact, this figure clearly shows that L11.3 is much more inconsistent with IASI than L8.1. This is a pathology, which has been also evidenced by Shephard et al. (2009). 


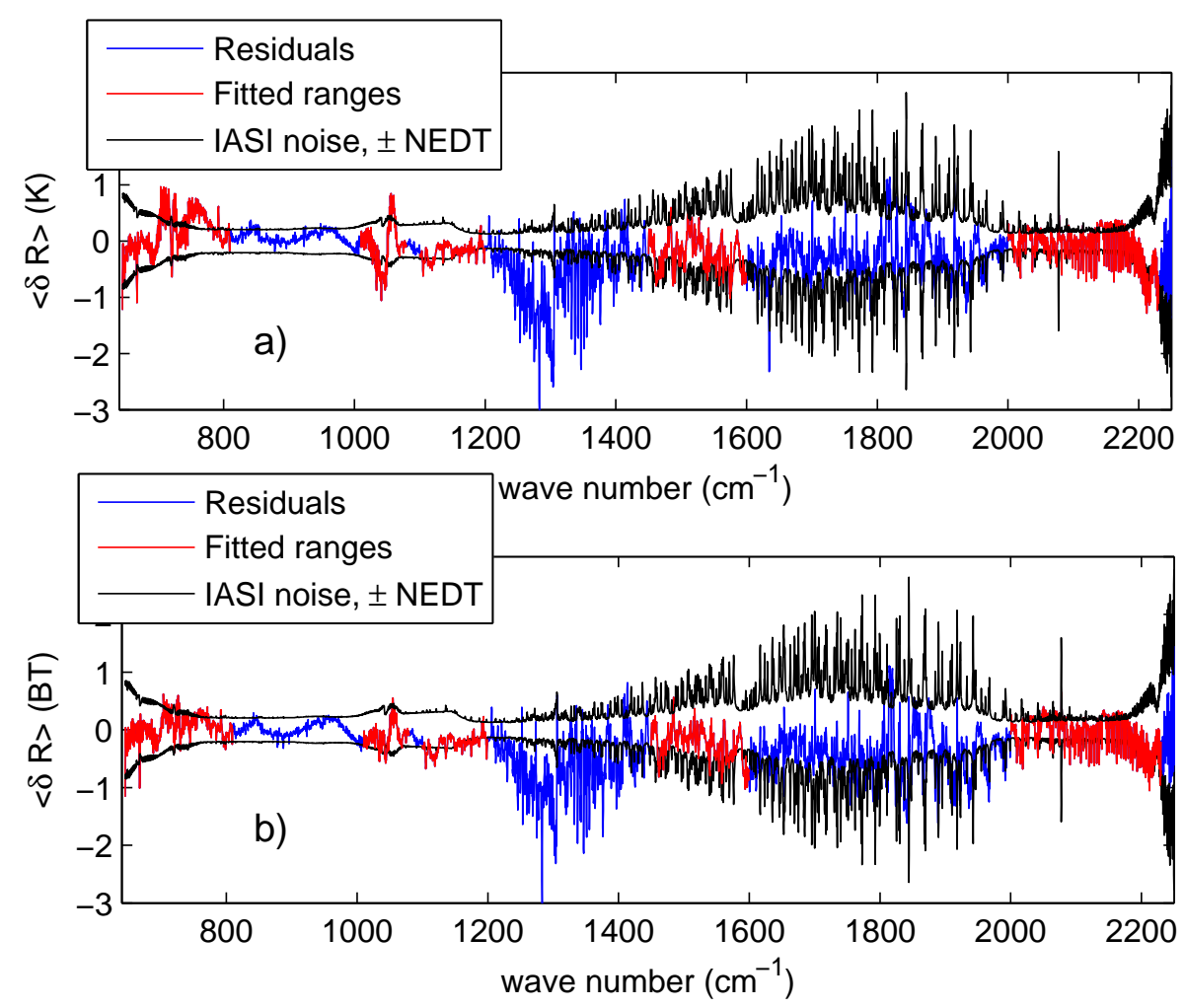

Fig. 9. As Fig. 8, but in units of brightness temperature (K). To improve reading, only the spectral coverage of interest to inversions for geophysical parameters is shown.
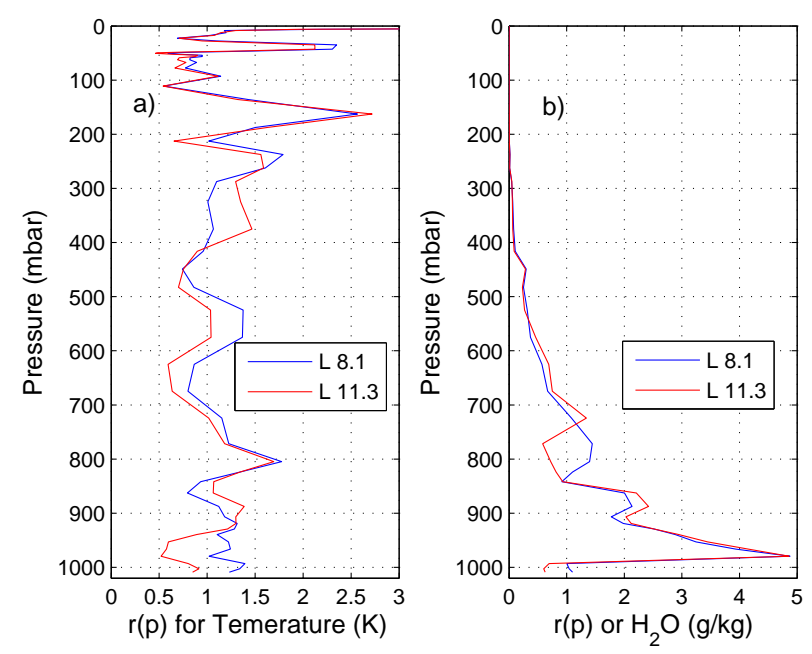

Fig. 10. JAIVEx experiment. Root mean square difference $(r$ in figure) computed by contrasting IASI retrievals against radiosonde observations. Values have been averaged over the data set of 25 IASI soundings. (a) temperature; (b) water vapour. The blue and red lines correspond to the two versions of $\sigma$-IASI, L8.1 and L11.3 respectively. used in the analysis (see text for discussion).

\subsection{Inversion results for the tropical data set}

Also for this case, retrievals were obtained for the two versions of $\sigma$-IASI we are dealing with in this paper: L8.1 and L11.3.

Figures from 13 to 15 summarize the performance of the scheme for temperature, water vapour and ozone, respectively. The performance has been quantitatively evaluated by considering, for any pressure level, $p$, the bias, $b(p)$ and the root mean square difference, $r(p)$, defined as in Eq. (4) and Eq. (5), where now the role of the test profiles is played by the ECMWF profiles, and the number of test cases is $m=647$.

For temperature we found that the bias is confined within $\pm 1 \mathrm{~K}$ in the lower troposphere, where the root mean square difference ranges in between $1-2 \mathrm{~K}$. Considering that the ECMWF temperature profile is credited of an accuracy within $0.5-1 \mathrm{~K}$, the results we have found are quite close to the expected accuracy of $1 \mathrm{~K}$ for the troposphere.

Figures 13 to 15 also allow us to compare the performance achieved with the two different $\sigma$-IASI models. In this respect, it is seen that no clear superiority of one version over the other is evidenced. However, L11.3 seems to perform slightly worse than L8.1. Nevertheless, we confirm that L11.3 yields a better consistency with IASI observations, as it is possible to see from Fig. 16. Concerning this last figure, 

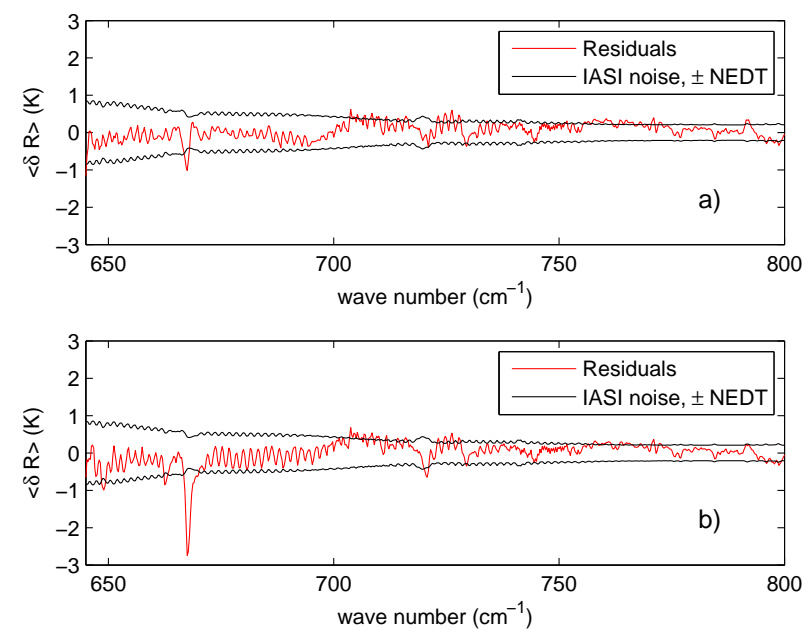

Fig. 11. Spectral residual (in brightness temperature units) averaged over the 25 JAIVEx IASI soundings analyzed in this paper for the range 645 to $800 \mathrm{~cm}^{-1}$ and for the case L11.3. (a) the inversion has been initialized with our EOF regression based First Guess; (b) the inversion has been initialized with sonde observations continued in the upper atmosphere with the ECMWF analysis. The comparison evidences a possible inconsistency of the ECMWF temperature profiles in the stratosphere

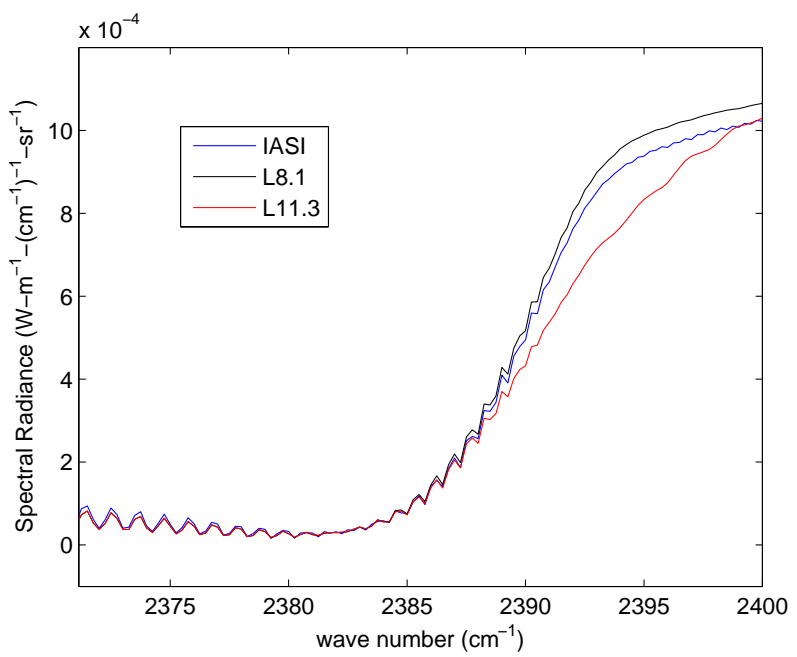

Fig. 12. IASI and fitted spectra (averaged over the 25 JAIVEx IASI soundings) for the two cases L8.1 and L11.3 at the $\mathrm{CO}_{2} v_{3}$ band head, showing the relevant inconsistency of L11.3 when compared to the IASI observations.

it is important also to stress that we could obtain converged retrieved solutions, in the $\chi^{2}$ sense (see section 2.2.1) only by a proper tuning of the inconsistency factor, $f^{2}$. For both L8.1 and L11.3 we could run with $f^{2}=3$, so that the spectral residual has a larger variability than that seen for the JAIVEx experiment, e.g. compare Fig. 8 with Fig. 16.
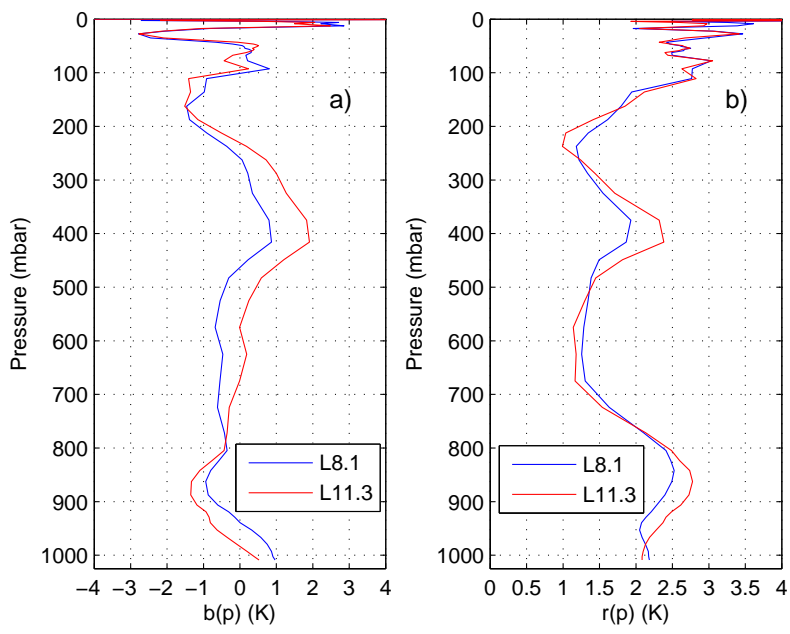

Fig. 13. Averaged linear difference ( $b$ in figure) and root mean square difference ( $r$ in figure) between IASI temperature retrieval and ECMWF. Values have been averaged over the full tropical data set of 647 IASI soundings.
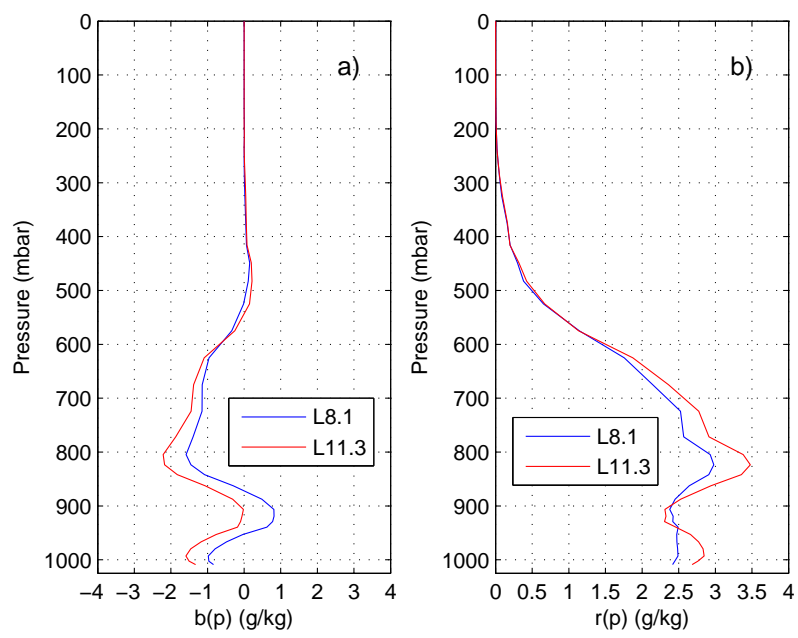

Fig. 14. As Fig. 13, but for water vapour.

The fact that L11.3 seems less consistent with ECMWF, while exhibiting a higher consistency with IASI observations, deserves attention. To this end, we recall that our EOF regression, which is used for initializing the inversion is trained on the ECMWF Chevalier (2001) data set, and, therefore, it is inherently consistent with ECMWF analysis. Thus, the better retrieval consistency of L8.1 with ECMWF simply says that the final solution remains closer to the First Guess. In the end, L11.3 finds a better spectral consistency with IASI at a solution point, which is further from the first guess. If we are right, the ECMWF analysis should be less consistent to IASI observations than our final L11.3 solution. 

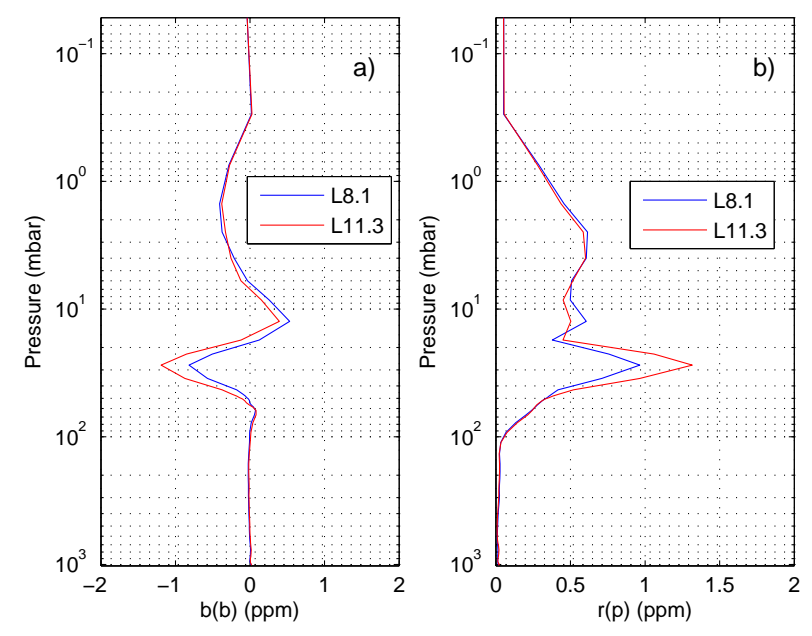

Fig. 15. As Fig. 13, but for ozone.

In fact this is the case, as shown by Matricardi (2009) who have found a consistent discrepancy at $667 \mathrm{~cm}^{-1}$ in the core of the $\mathrm{CO}_{2}$ absorption band by running diverse forward models with co-located ECMWF profiles. Our results allows to clarify that rather than a problem of forward modeling, that inconsistency is a problem of the ECMWF analysis itself.

\section{Conclusions}

We have performed a series of retrieval exercises using IASI tropical soundings, two different compilations for absorption line and continuum parameters, two corresponding different implementations of a fast forward model, built upon a stateof-art radiative transfer model.

State of art radiative transfer is consistent with IASI provided we introduce a forward modeling pseudo-noise whose magnitude is 0.5 to 2 times the current IASI radiometric noise. However, this noise shows a non-random component whose analysis allows us to have very clear diagnosis about where and how forward modeling and spectroscopy fail and, therefore, have to be improved in order to yield a better consistency among observations and calculations.

Our findings say that the new line mixing treatment provided by Niro et al. (2005) is capable of reducing the spectral residual within the IASI noise in the fundamental $\mathrm{CO}_{2} v_{2}$ band. Some open issues still remain for the $v_{3}$ band, whose modeling has to be improved. A result which has been arrived at also by LBLRTM authors (see e.g. Shephard et al. (2009)). We plan to further investigate and address the problem of $\mathrm{CO}_{2}$ spectroscopy and line mixing by performing a comparison of the present results with those obtained using the Strow/DeSouza-Machado $\mathrm{CO}_{2}$ data base which includes line mixing (e.g. Strow et al. (2003)).
Based on the JAIVEx experiment the new line treatment consistently improves the accuracy of temperature retrieval. The comparison with ECMWF co-located profiles shows some mixed results, which is seemingly due to a deficiency of the ECMWF analysis, rather than a problem of the new line mixing scheme adopted in LBLRTM version 11.3.

The spectral residual for the ozone band at $9.6 \mu \mathrm{m}$ also improves in comparison to the old version L8.1, although the spectral residual is not reduced to a random noise. Finally, water vapour absorptions parameters seem to be of enough quality to produce a negligible bias, at least in the spectral residual. However, mostly for this case, line and continuum absorptions need to be improved.

As far as the accuracy of retrieval is concerned, it has been shown that state-of-the-art radiative transfer allows us to invert IASI data for temperature with an accuracy quite close to the target performance of $1 \mathrm{~K}$ in the troposphere. For water vapour we are in a range of accuracy for the lower troposphere of around 10 to $20 \%$. However, even improving the accuracy of radiative transfer, the goal accuracy of $10 \%$ in the lower troposphere appears very difficult to achieve.

Compared to simulations, real retrievals show a comparable root mean square error. However, the bias goes up and becomes the dominant factor in the root mean square error. This bias is the result of the aforementioned forward modeling pseudo noise, which demands for new basic research in order to be zeroed. In this context, the very good quality of IASI data could play a significant role, both for the assessment of this bias and to lead to suitable schemes to remove such a systematic component from forward models.

Finally, our results are comparable to those shown by other authors (see e.g. Zhou et al., 2009), although our findings hint at a better performance for temperature and water vapour. However, it should be stressed that our methodology is not intended for operational purposes, as it is the case for other schemes. The package $\varphi$-IASI is mostly intended to address remote sensing research issues, and to get insight into understanding the capability of modern infrared satellite sensors and the impact of possibly new and improved spectroscopy.

Acknowledgements. Work dedicated to Professor Antonio Mario Tamburro.

We thank S. A. Clough and M. Shephard, co-author of LBLRTM, for the valuable comments and critical reading of the manuscript.

IASI has been developed and built under the responsibility of the Centre National d'Etudes Spatiales (CNES, France). It is flown onboard the Metop satellites as part of the EUMETSAT Polar System. The IASI L1 data are received through the EUMETCast near real time data distribution service. We thank Dr Stuart Newman (Met Office) for providing the JAIVEx data. The JAIVEx project has been partially funded under EUMETSAT contract Eum/CO/06/1596/PS. The FAAM BAe 146 is jointly funded by the Met Office and the Natural Environment Research Council. The US JAIVEx team was sponsored by the National Polar-orbiting Operational Environmental Satellite System (NPOESS) Integrated Program Office (IPO) and NASA. 

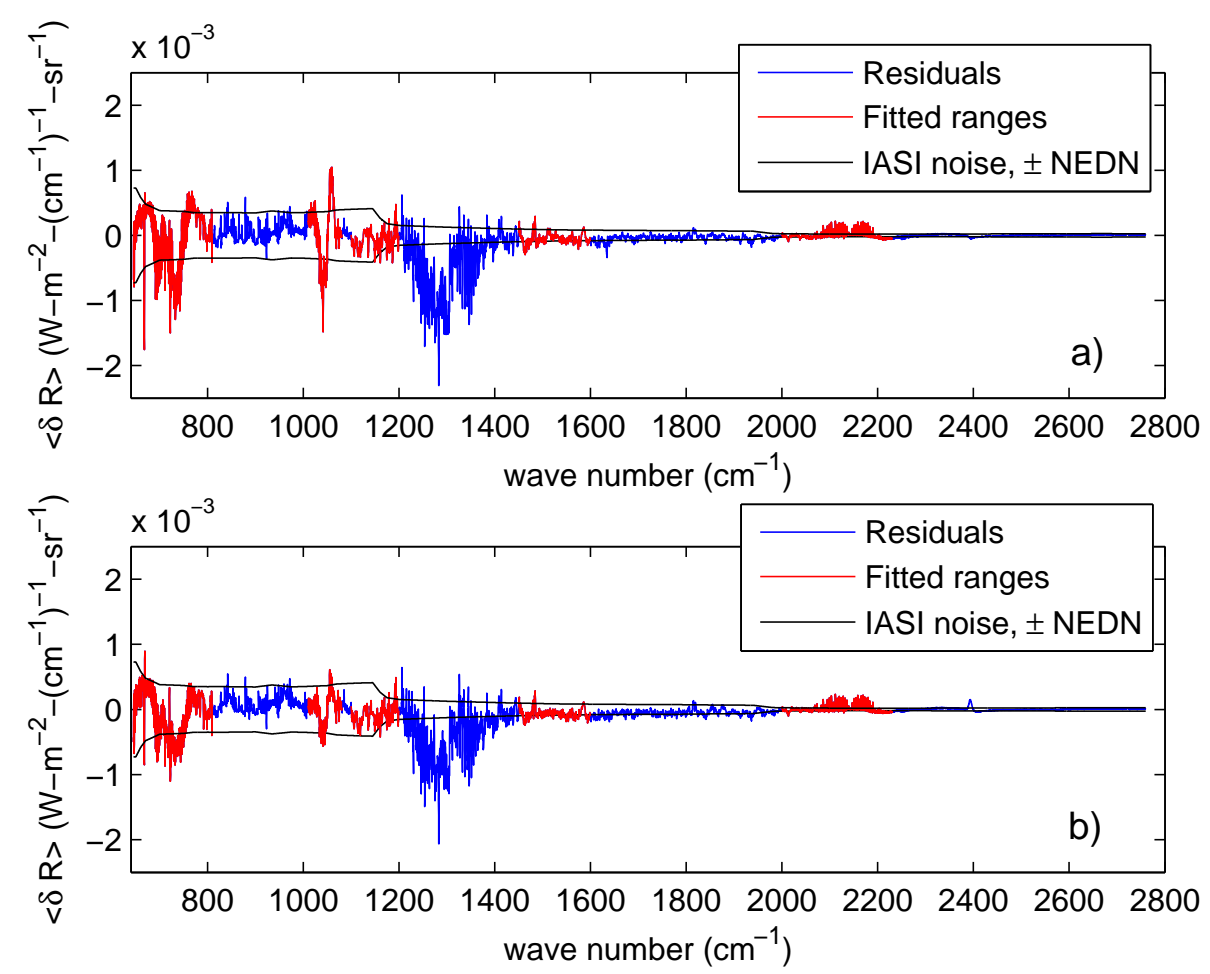

Fig. 16. Spectral residual, $\delta \mathbf{R}$ averaged over the 647 tropical IASI soundings analyzed in this paper. (a) spectral residual for the case L8.1, (b) spectral residual for the case L11.3. The residuals in red corresponds to the spectral ranges, which have been used in the inversion process.

Edited by: A. Richter

\section{References}

Amato U., Cuomo V., and Serio C., Assessing the impact of radiometric noise on IASI performances Int. J. Remote Sens., 16(15), 2927-2938, 1995.

Amato U., and Serio C., The impact of random noise on the perfromance of a new infrared atmopsheric sounding interferometer (IASI) configuration, Int. J. Remote Sens., 18(15), 3135-3143, 1997.

Amato U., Cuomo V., Rizzi R., and Serio C., Evaluating the effect of the inter-relationship among the different spectral bands on IASI performance, Q. J. Roy. Meteor. Soc., 123, 2231-2244, 1997.

Amato, U., De Canditiis, D., and Serio, C.: Effect of Apodization on the Retrieval of Geophysical Parameters from FourierTransform Spectrometers, Appl. Optics, 37, 6537-6543, 1998.

Amato, U., Masiello, G., Serio, C., and Viggiano, M.: The $\sigma$-IASI code for the calculation of infrared atmospheric radiance and its derivatives, Environ. Modell. Softw., 17/7, 651-667, 2002.

Amato U, Antoniadis A., De Feis I., Masiello G., Matricardi M., and Serio C.: Technical note: Functional sliced inverse regression to infer temperature, water vapour and ozone from IASI data, Atmos. Chem. Phys., 9, 5321-5330, 2009, http://www.atmos-chem-phys.net/9/5321/2009/.
Anderson, G. P., Clough, S. A., Kneizys, F. X., Chetwind, J. H., and Shettle, E. P.: AFGL Atmospheric concentration profiles (0$120 \mathrm{~km}$ ), AFGL-TR-86-0110, AFGL (OPI), Hanscom AFB, MA 01736, USA, 1986.

Backus, G. and Gilbert, F.: The resolving power of gross Earth data, Geophys. J. Roy. Astr. S., 16, 169-205, doi:10.1111/j.1365246X.1968.tb00216.x, 1968.

Bizzarri, B.: Historical background for IASI, in: High Spectral Resolution Infrared Remote Sens. for Earth's Weather and Climate Studies, edited by: Chedin, A., Chahine, M. T., Scott, N. A., NATO ASI Series, I 9, Springer Verlag, Berlin-Heidelberg, Germany, 3-7, 1993.

Carissimo, A., De Feis, I., and Serio, C.: The physical retrieval methodology for IASI: the $\delta$-IASI code, Environ. Modell. Softw., 20, 1111-1126, 2005.

Carissimo, A., Grieco, G., Masiello, G., Matricardi, M., and Serio, C.: Application of the $\sigma$-IASI radiative transfer model to IASI, Current problems in atmospheric radiation (IRS 2008): Proceedings of the International Radiation Symposium (IRC/IAMAS), Foz do Iguaçu, Brazil, 3-8 August 2008, AIP publishers, Melville NY, USA, 31-34, 2009.

Cayla, F.-R., IASI infrared interferometer for operations and research, in: Chedin, A., Chahine, M.T., Scott, N.A. (Eds.), High Spectral Resolution Infrared Remote Sens. for Earth's Weather and Climate Studies. NATO ASI Series, I 9, Springer Verlag, Berlin-Heidelberg, Germany, 9-19, 1993.

Chevalier, F.: Sampled database of 60 levels atmospheric profiles from the ECMWF analysis, Tech. Rep., ECMWF EUMETSAT 
SAF programme Research Report 4, 2001.

Clough, S. A., Shephard, M. W., Mlawer, E. J, Delamere, J. S., Iacono, M. J., Cady-Pereira, K., Boukabara, S., and Brown, P. D.: Atmospheric radiative transfer modeling: a summary of the AER codes, J. Quant. Spectrosc. Rad., 91, 233-244, doi:10.1016/j.jqsrt.2004.05.058, 2005.

Eremenko, M., Dufour, G., Foret, G., Keim, C., Orphal, J., Beekmann, M., Bergametti, G., and Flaud, J.-M.: Tropospheric ozone distributions over Europe during the heat wave in July 2007 observed from infrared nadir spectra recorded by IASI, Geophys. Res. Lett., 35, L18805, doi:10.1029/2008GL034803, 2008.

Gordon, I. E., Rothman, L. S., Gamache, R. R., Jacquemart, D., Boone, C., Bernath, P. F., Shephard, M. W., Delamere, J. S., and Clough, S. A.: Current updates of the water-vapor line list in HITRAN: A new diet for air-broadened half-widths, J. Quant. Spectrosc. Rad., 108, 389-402, doi:10.1016/j.jqsrt.2007.06.009, 2007.

Grieco, G., Luchetta, A., Masiello, G., Serio, C., and Viggiano, M.: IMG $\mathrm{O}_{3}$ retrieval and comparison with TOMS/ADEOS columnar ozone: an analysis based on tropical soundings, J. Quant. Spectrosc. Rad., 95, 331-348, 2005.

Grieco, G., Masiello, G., Matricardi, M., Serio, C., Summa, D., and Cuomo, V.: Demonstration and validation of the $\varphi$-IASI inversion scheme with NAST-I data, Q. J. Roy. Meteor. Soc., 133(S3), 217-232, 2007.

Masiello, G., Serio, C., and Shimoda, H.: Qualifying IMG Tropical Spectra for Clear Sky, J. Quant. Spectrosc. Rad., 77(2), 131-148, 2003.

Masuda, K., Takashima, T., and Takayama, Y.: Emissivity of pure and sea waters for the model sea surface in the infrared window regions, Remote Sens. Environ., 24, 313-329, 1988.

Matricardi, M.: Technical Note: An assessment of the accuracy of the RTTOV fast radiative transfer model using IASI data, Atmos. Chem. Phys., 9, 6899-6913, 2009,

http://www.atmos-chem-phys.net/9/6899/2009/.

Niro, F., Jucks, K., and Hartmann, J.-M.: Spectra calculations in central and wing regions of $\mathrm{CO}_{2}$ IR bands, IV : Software and database for the computation of atmospheric spectra, J. Quant. Spectrosc. Rad., 95, 469-481, doi:10.1016/j.jqsrt.2004.11.011, 2005.

Rodgers, C. D.: Retrieval of atmospheric temperature and composition from remote measurements of thermal radiation, Rev. Geophys. Space Ge., 14, 609-624, 1976.

Rothman, L. S., Barbe, A., Benner, D. C., Brown, L. R., CamyPeyret, C., Carleer, M. R., Chance, K., Clerbaux, C., Dana, V., Devi, V. M., Fayt, A., Flaud, J.-M., Gamache, R. R., Goldman, A., Jacquemart, D., Jucks, K. W., Lafferty, W. J., Mandin, J.-Y., Massie, S. T., Nemtchinov, V., Newnham, D. A., Perrin, A., Rinsland, C. P., Schroeder, J., Smith, K. M., Smith, M. A. H., Tang, K., Toth, R. A., Vander Auwera, J., Varanasi, P., and Yoshino, K.: The HITRAN molecular spectroscopic database: edition of 2000 including updates through 2001, J. Quant. Spectrosc. Rad., 82, 5-44, doi:10.1016/S00224073(03)00146-8, 2003.
Rothman, L. S., Jacquemart, D., Barbe, A., Benner, D. C., Birk, M., Brown, L. R., Carleer, M. R., Chackerian, C., Chance, K., Coudert, L. H., Dana, V., Devi, V. M., Flaud, J. M., Gamache, R. R., Goldman, A., Hartmann, J. M., Jucks, K. W., Maki, A. G., Mandin, J. Y., Massie, S. T., Orphal, J., Perrin, A., Rinsland, C. P., Smith, M. A. H., Tennyson, J., Tolchenov, R. N., Toth, R. A., Vander Auwera, J., Varanasi, P., and Wagner, G.: The HITRAN 2004 molecular spectroscopic database, J. Quant. Spectrosc. Rad., 96, 139-204, doi:10.1016/j.jqsrt.2004.10.008, 2005.

Serio, C., Masiello, G., and Grieco, C.: EOF regression analytical model with applications to the retrieval of atmospheric temperature and gas constituents concentration from high spectral resolution infrared observations, in: Environmental Modelling: New Research, edited by: Findley, P. N., Nova Science Publishers, Inc., Hauppagauge, NY, USA, 51-88, ISBN: 978-1-60692-0343, 2009.

Serio, C., Esposito, F., Masiello, G., Pavese, G., Calvello, M. R., Grieco, G., Cuomo, V., Buijs, H. L., and Roy, C. B.: Interferometer for ground-based observations of emitted spectral radiance from the troposphere: evaluation and retrieval performance, Appl. Optics, 47(21), 3909-3919, 2008.

Shephard, M. W., Clough, S. A., Payne, V. H., Smith, W. L., Kireev, S., and Cady-Pereira, K. E.: Performance of the line-by-line radiative transfer model (LBLRTM) for temperature and species retrievals: IASI case studies from JAIVEx, Atmos. Chem. Phys., 9, 7397-7417, 2009, http://www.atmos-chem-phys.net/9/7397/2009/.

Strow, L. L., Hannon, S. E., De Souza-Machado, S., Motteler, H. E., and Tobin, D.: An Overview of the AIRS Radiative Transfer Model, IEEE T. Geosci. Remote Sens., 41(2), 303-313, 2003.

Taylor, J. P.: Principal Investigator, Joint Airborne IASI Validation Experiment, online available at: http://badc.nerc.ac.uk/data/ jaivex/.

Taylor, J. P., Smith, W. L., Cuomo, V., Larar, A. M., Zhou, D. K., Serio, C., Maestri, T., Rizzi, R., Newman, S., Antonelli, P., Mango, S., Di Girolamo, P., Esposito, F., Grieco, G., Summa, D., Restieri, R., Masiello, G., Romano, F., Pappalardo, G., Pavese, G., Mona, L., Amodeo, A., and Pisani, G.: EAQUATE An International Experiment For Hyper-spectral Atmospheric Sounding Validation, B. Am. Meteorol. Soc., 89(2), 203-218, doi:10.1175/BAMS-89-2-203, 2008.

Tobin, D. C., Best, F. A., Brown, P. D., Clough, S. A., Dedecker, R. G., Ellingson, R. G., Garcia, R. K., Howell, H. B., Knuteson, R. O., Mlawer, E. J., Revercomb, H. E., Short, J. F., van Delst, P. F. W., and Walden, V. P.: Downwelling spectral radiance observations at the SHEBA ice station: Water vapor continuum measurements from 17 to $26 \mu \mathrm{m}$, J. Geophys. Res., 4(D2), 2081-2092, 1999.

Zhou, D. K., Smith, W. L., Larar, A. M., Liu, X., Taylor, J. P., Schlüssel, P., Strow, L. L., and Mango, S. A.: All weather IASI single field-of-view retrievals: case study - validation with JAIVEx data, Atmos. Chem. Phys., 9, 2241-2255, 2009, http://www.atmos-chem-phys.net/9/2241/2009/. 